\title{
\$? ГОСУДАРСТВЕННЫЕ ИНСТИТУТЫ
}

Павлов В.С., Масланов Д.В.

\section{ЗАРУБЕЖНЫЙ ВЗГЛЯД НА РОССИЙСКИЙ ПОСТСОВЕТСКИЙ ПАРЛАМЕНТ 1994 - 2007 гг.}

\begin{abstract}
Аннотация: Предметом данного исследования является взгляд зарубежных, в частности англо-американских, исследователей на один из важнейших институтов государственной власти любой страны - Парламент, в данном случае, на Государственную Думу Федерального Собрания Российской Федерации. Восприятие России в общественном сознании западных стран всегда отличалось противоречивостью, граничащей с неодобрением и осуждением, что в целом соответствует общему характеру отношений между Россией и Западом. Если говорить о зарубежных исследованиях российского демократического транзита, то для многих авторов основным элементом анализа становится Президент России, но также есть пул исследований посвященных и законодательной ветви власти. Авторами рассматриваются несколько наиболее показательных статей развитии российского Парламента первых 4 созывов, исходя из этого прослеживается их взгляд на генезис данного института. Новизна исследования заключается в использовании нескольких слабо изученных работ по данной проблематике на оригинальном языке. Проанализировав их авторы приходят к выводу о том, что отношения к парламенту меняется с течением времени, что коррелирует с отношением западного сообщества к российской действительности. Их описания разнятся от самого "демократического" парламента в времена Б.Н. Ельцина, до ручного парламента Администрации Президента во время президентства В.В. Путина. Ключевые слова: Б.Н. Ельиин, В.В. Путин, Государственная Дума РФ, Демократический транзит, Администрация Президента, Россия, Принци разделения властей, Политические партии, Парламентский контроль, Суперпрезидециализм.
\end{abstract}

Abstract: The subject of this research is the view of the foreign and particularly English-American scholars upon one of the imperative institutions of state authority of any country - the Parliament, or in this case, the State Duma of the Federal Assembly of the Russian Federation. The perception of Russian in public consciousness of Western countries has always been synonymous with controversy, bordering disapproval and condemnation, which generally reflects the overall relationship between Russian and the West. The foreign researchers of the Russian democratic transit demonstrate that the main vector of the analysis lies in the President of the Russian Federation, but we can also observe pool of the research dedicated to the legislative branch of authority. The authors examine several most illustrative articles on the development of the Russian Parliament of the first four convocations, and based on this, their view upon the genesis of this institution can be traced. The scientific novelty consists in the use of particular little-studied works on this topic on the language of origin. Analyzing these works, the authors conclude that the attitude towards the Parliament changes with time, which correlates with the relation of the Western society regarding the Russian reality. The descriptions differ from the very "democratic" parliament during the time of B. N. Yeltsin to the rubber-stamp parliament of the Presidential Administration during V. V. Putin's presidency.

Keywords: Superpresidentialism, Parliamentary control, Political parties, Principle of separation of powers, Russia, Presidential Administration, Democratic transit, State Duma of the Russian Federation, V. V. Putin, B. N. Yeltsin.

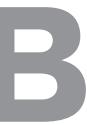

осприятие России в общественном сознании западных стран всегда отличалось противоречивостью, граничащей с неодобрением и осуждением, что в целом соответствует общему характеру отношений между Россией и Западом. Если говорить о зарубежных исследованиях российского демократического транзита, то для многих авторов основным элементом анализа становится Президент России. Но изучением института президентской власти, так называемым «суперпрезиденциализмом», дело, естественно, не ограничивается. Есть пул исследований, которые берут для рассмотрения другие важные институты государства, которые существенно влияют на развитие политической системы страны $[1 ; 2 ; 3]$.

В данной статье авторы заостряют внимание на отражении в зарубежных исследованиях 
российского законодательного органа власти Государственной Думы Федерального Собрания Российской Федерации (далее - Дума). Для более четкого выделения проблематики авторами были проанализированы наиболее показательные мнения англо-американских исследователей о Думе первых 4 созывов как об институциональном образовании, так и о её функциях и изменениях её влияния на политический процесс в стране.

Если говорить об особенностях исследования данного института, то стоит признать, что его специфика в том, что в отличие от Президента его состав менялся каждые 4 года. Таким образом, за время пребывания на посту двух президентов успело смениться 4 состава Государственной Думы, в которых доминировали различные политические силы, находившиеся в разных отношениях как с исполнительной властью в целом, так и с Президентом в частности.

Нил Робертсон отмечает, что Дума является главным законодательным органом государства, но ее влияние на исполнительную власть и эффективность как надзорного органа была снижена ее организационной структурой [4. p. 152]. Это отмечается по отношению к Думе, которая существовала до прихода к власти В.В.Путина, то есть до 1999 года. Но стоит заметить, что исследователи, которые вплотную занимаются проблематикой организации уже «путинского парламента», также отмечают проблему организационной структуры [5, p. 1000-1003]. Кроме того, исследователи отмечают, что российская конституция, давая большие полномочия президенту, никак не определяет функции надзора за ним и его администрацией. По мнению политолога, преподавателя Университета Оксфорд-Брукс Сары Уитмор «Конституция РФ 1993 года не содержит эксплицитного упоминания о контрольной роли Федерального Собрания, но это вполне нормально: например в конституциях США или ФРГ она также не упоминается. Однако контроль над деятельностью правительства напрямую вытекает из положений, которые касаются разделения властей $<\ldots>$ » [6]. Таким образом, парламент не может контролировать ни силовые министерства, которые подчинены напрямую президенту, ни администрацию президента, которая формируется параллельно правительству [5, p. 1002-1003].

Если возвращаться непосредственно к Думе времен Б.Н. Ельцина, которая занимает особое место в исследованиях развития политических институтов России, то стоит отметить мнение Пола Чейсти, профессора Оксфордского университета, полагающего, что Дума часто сама себя зажимала в тиски тем, что думские комитеты и думские фракции работа- ли с различной повесткой дня. Комитеты давали огромное количество законопроектов, но лидерство в думе принадлежало, как пишет Чейсти, «советской» фракции. Поэтому принятие законопроектов держалось на распрях, а думские фракции боролись, чтобы сформировать выигрышную коалицию в меняющихся настроениях населения, к представленным в «советской» Думе фракциям [7, р. $104-108]$. Этим усугубляется работа думских комитетов, усиливая соперничество между ними. И они не могут найти правильные координаты в работе, потому что не имеют голоса и возможности давления на Думу. Более того, никогда не имея про или антиправительственного большинства, Дума не могла серьезно координировать свои действия и эффективно определять какие законопроекты приоритетны и должны быть приняты $[8$, p. 45]. Нил Робертсон в этой связи также замечает, соглашаясь с Полом Чейсти, что такая структура не могла соперничать с президентской властью, но это был самый успешный представительный институт в истории России, в котором были механизмы кооптации оппозиции в политическую систему страны. Это давало большой эффект и его успех позволял ей преодолевать недостатки институциональной конструкции и конституционных ограничений. Хотя именно это обуславливало ее слабость перед исполнительной властью. И все же, - как отмечает Нил Робертсон, - структура ее была достаточно гибкой, что бы примерить большие различия и не допустить превращения в политический цирк. Конечно, были «показные выступления, вроде оскорблений или драк, но в целом Думе удалось выработать консенсус о том как работать, что и позволило ей выжить [4, p. 152 - 154]. Многие англо-американские исследователи полагают, что парламент после 1993 года и до конституционного большинства «Единой России» в 4 созыве, был истинно демократическим, в котором было место как оппозиционным, так и проправительственным мнениям, и многие вопросы решались в тяжелых дискуссиях, что является неотъемлемой часть настоящей представительной демократии. Сара Уитмор отмечает, что при Б.Н. Ельцине в Думе проходило огромное количество слушаний по различным вопросам. Отчетность правительства перед парламентом, по сравнению с путинскими временами, была феноменальной [5, p. 1004]. Она замечает, что при первом президенте России, когда институционально оформился, «суперпрезиденцинализм», думские комитеты инициировали большое количество депутатских расследований, антикоррупционных запросов, по ним созывались специальные слушания по анти коррупционным делам. Ежемесячно перед 


\section{Право и политика $12(204) \cdot 2016$}

Думой отчитывалось правительство, так или иначе за Думой была закреплена очень большая надзорная функция [5, p. 1004 - 1006]. Известный исследователь российской истории и институциональной системы Томас Ремингтон, считает, что российская Дума - это уникальный институт в истории России. Это истинный национальный форум для обсуждения вопросов политики, - пишут Т. Ремингтон и Р. Смит. Они показывают в своей статье, что «<... Дума после 1993 года была очень разнообразной и это разнообразие ни одному интересу не позволяло полностью доминировать на другими» [9, р. 545- 558]. «И даже когда коммунисты получили большинство в парламенте, - пишет Ричард Саква, - в 1995 году, они не могли себе позволить не считаться с другими партиями, они имели малые ресурсы в политической системе и должны были сотрудничать, что бы избежать роспуска парламента» [10]. Многими исследователями также было отмечено, что российский парламент, имея способность представить свой единый образ, получил возможность принять много законопроектов, и чаще чем обычно успешно торговаться с президентом по многим ключевым вопросам [9; 11; 12].

Всеми исследователями отмечается, что переход к «новому виду» Думы, читай «зависимой», резко обозначился в период президентства В.В. Путина [5, p. 1002-1003]. Как пишет Томас Ремингтон, даже избрание Совета Федерации было изменено, что также было сделано ради уменьшения влияния региональных властей на принятие решений [13, p. 671]. По его мнению, еще в Думе 1999 года большинство было не за проправительственными партиями, и Путину необходимо было договариваться с представителями оппозиции [11, p. 286; 9]. Но принятие закона о партиях, который позволил в 2003 году избрать большинство от «Единой России» по одномандатным округам, по существу сделало Думу представительным органом исполнительной власти [13, p. 675]. Пол Чейсти в этой связи замечает, что в начале путинской Думы 2003 года почти все инициативы правительства стали приниматься буквально за один день, что было не типично для предыдущих созывов [14, p. 98]. Сара Уитмор, как уже отмечалось выше, указывала на то, что в ельцинских Думах наблюдательная функция парламента над правительством была очень сильна, но уже в начале президентства В.В. Путина всё начинает меняться, и Дума становится отделом Администрации Президента. Она же, в свою очередь становится безотчетна, потому что большинство за проадминистративной партией. С. Уитмор утверждает, что чем больше B.В. Путин был у власти, тем меньше становился уровень надзора, особенно в сфере расследований за злоупотреблениями. Томас Ремингтон в этой связи отмечает, что в третьем созыве количество думских запросов на антикоррупционные расследования было большим, но даже это было инструментом В.В. Путина для решения увольнения проблемы увольнения некоторых министров [15, р. 967 - 968]. «Но в четвертом созыве Думы, - пишет Сара Уитмор, - когда большинство становится у Единой России, эта функция отходит к Счетной Палате, которая представляется как часть президентской администрации» [5, p. 1006]. Вместе с тем отмечается, что институционально Дума не претерпела особых изменений. Сара Уитмор даже считает, что де-юре функции парламента расширились, возможности комитетов были увеличены, правительственный час удлинен, надзор медиа над Думой стал очень серьезный, но де-факто они маргинализировалась [5]. Ричард Саква определяет это тем, что в путинской России наметилось противоречие между де-факто тенденциями к однопартийной системе и существующей де-юро плюралистической системой [16, p. 884]. Более того, Дума стала легитимацией режима и лобби для бизнеса: Кремль дает Единой России ресурсы, а Единая Россия Кремлю скорейшее решение вопросов [5, p. 1021 - 1023].

В целом, можно отметить, что отношение к парламенту у англоязычных исследователей меняется с течением времени, равно как меняется их отношение к России в целом. Сначала, когда в Думе господствовал дух плюрализма, было большое количество партий и ни у одной из них не было большинства- они соглашаются, что у нее были проблемы, были и «показательные выступления» отдельных депутатов, фракций, но в целом она умела договариваться, некоторые даже называют ее самой демократической в истории России. После прихода к власти В.В. Путина власть начинает упорно работать над выстраиванием вертикали власти для более эффективной работы всех её ветвей, для так называемой симофнии, то, естественным образом уменьшается и плюрализм мнений. Когда же в Думе четвертого созыва появляется еще и явное проправительственное большинство - исследовательский тон сразу меняется на негативный. Нельзя сказать, что это не оправданно: большинство из отмеченных авторами процессов имели место быть. Но, вероятно, тут стоит говорить о том, что не всегда централизация и, если выражаться словами Ричарда Саквы, компактизация политического поля негативна. «Во многих странах, - как отмечает Сара Уитмор, - существует сниженная активность парламента по надзору, но это не должно было принимать такой широкий масштаб» [5, p. 1018]. Многие мнения по поводу деятельности российской власти, в том числе законодательной, но- 
сят отпечаток отношения западных стран к российскому президенту и политической системе, которая возникла на месте советской. Многие отмечают, что в России не произошло демократического транзита по европейскому образцу [2; $3 ; 17]$. Но необходимо учитывать, что в сложные периоды времени, когда нужно быстрое решение многих вопросов, когда нет времени на долгие политические споры, поддержка «супер-президентом» и его сильной администрацией одной партии является единственным выходом. Но, несомненно, нельзя делать эту меру решения слож- ных вопросов постоянной, правительство должно быть подотчетно парламенту, оно должно само предоставлять возможность себя контролировать для того, что бы в диалоге с представительной властью исполнять свои обязанности более эффективно. В этом, в том числе, и состоит смысл разделения ветвей власти. Но принимавшиеся постановления, законы говорят о том, что власть дает такие возможности, парламенту только необходимо было тогда, и даже уже сейчас надо иметь политическую волю, что бы ими воспользоваться.

\section{Библиография:}

1. Линц, X. Опасности президентства-URL: http://www.gumer.info/bibliotek_Buks/Polit/Article/lin_opasn.php. - Библиотека Гумер (дата обращения: 05.05.2013).

2. Лукин А.В. Переходный период в России: демократизация и либеральные реформы // Полис. 1999. № 2 С. 134-155.

3. Шевцова Л.Ф. Смена режима или системы? // Полис. 2004. №1 С. 46-51.

4. Robinson N. The Politics of Russia's Partial Democracy / Political studies review - 2003. - Vol.1 - P. 149 - 166.

5. Whitmore S. Parliamentary Oversight in Putin's Neo-Patrimonial State. Watchdogs or Show-dogs? // Europe-Asia Studies, - 2010. - №62 (6). Р. 999 - 1025.

6. Уитмор, С. Цтение молодости или плесень старости? Парламентский контроль в Государственной Думе четвертого созыва // Неприкосновенный запас. - URL: http://www.nlobooks.ru/sites/default/files/old/nlobooks.ru/rus/nzonline/619/828/839/index.html (дата обращения: 25.02.2016).

7. Chaisty P. Legislative Politics in Russia / in A. Brown Contemporary Russia Politics: a Reader. - Oxford: Oxford University Press, 2001. P. 21.

8. Chaisty P. Gleissner, J. The Consolidation of Russian Parliamentarism: The State Duma 1993 - 1998 / in N. Robinson ed. Institutions and Change in Russian Politics. - Basingstoke: MacMillan, 2000. P. 22.

9. Remington Thomas F., Smith Steven S. Theories of Legislative Institutions and the Organization of the Russian Duma // American Journal of Political Science, - 1998. - Vol. 42 / 2. - P. 543-569

10. Sakwa, R. Russian politics and society. London: Routledge, 2008. P. 32.

11. Remington Thomas F. The Russian Parliament: Institutional Evolution in a Transitional Regime, 1989 - 1999. - New Haven, CT \& London: Yale University Press, 2001. P. 23.

12. Chaisty P., Schleiter P. Productive but not Valued: the Russian State Duma, 1994 - 2001 // Europe-Asia Studies. - 2002. №54 (5). - pp. $701-724$.

13. Remington Thomas F. Majorities without Mandates: The Russian Federation Council Since $2000 / /$ Europe-Asia Studies. 2003. № 55(5). P. 667-691.

14. Chaisty P. Legislative Politics and Economic Power in Russia. - Basingstoke: Palgrave, 2006. P. 34.

15. Remington Thomas F. Patronage and the Party of Power: President - Parliament Relations Under Vladimir Putin // EuropeAsia Studies, - 2008. - №60 (6). - P. 959 - 987.

16. Sakwa R. Putin’s Leadership: Character and Consequences // Europe-Asia Studies, - 2008. - №60 (6). - P. 879 $-897$.

17. Цыганков А.П. Между либеральной демократией и сползанием в авторитаризм: предварительные итоги политического развития России // Социально-политический журнал. 1997. №1. С. 15 - 37.

18. Чепус А.В. Правительство Российской Федерации: состав и порядок его формирования // Политика и Общество. 2015. - 2. - C. 230 - 240. DOI: 10.7256/1812-8696.2015.2.14459.

19. Сергеева С.Л. Особенности национальной политической культуры: социокультурная специфика и перспективы развития в условиях современной российской действительности // Политика и Общество. - 2013. - 10. - С. 1286 - 1301. DOI: $10.7256 / 1812-8696.2013 .10 .9838$.

\section{References (transliterated):}

1. Lints, Kh. Opasnosti prezidentstva-URL: http://www.gumer.info/bibliotek_Buks/Polit/Article/lin_opasn.php. - Biblioteka Gumer (data obrashcheniya: 05.05.2013).

2. Lukin A.V. Perekhodnyi period v Rossii: demokratizatsiya i liberal'nye reformy // Polis. 1999. № 2 S. 134-155.

3. Shevtsova L.F. Smena rezhima ili sistemy? // Polis. 2004. №1 S. 46-51.

4. Robinson N. The Politics of Russia's Partial Democracy / Political studies review - 2003. - Vol.1 - P. 149 - 166.

5. Whitmore S. Parliamentary Oversight in Putin's Neo-Patrimonial State. Watchdogs or Show-dogs? // Europe-Asia Studies,-2010. - №62 (6). P. 999 - 1025. 
DOI: $10.7256 / 1811-9018.2016 .12 .18129$

При цитировании этой статьи сноска на doі обязательна

Право и политика $12(204) \cdot 2016$

6. Uitmor, S. Tstenie molodosti ili plesen' starosti? Parlamentskii kontrol' v Gosudarstvennoi Dume chetvertogo sozyva // Neprikosnovennyi zapas. - URL: http://www.nlobooks.ru/sites/default/files/old/nlobooks.ru/rus/nz-online/619/828/839/index. html (data obrashcheniya: 25.02.2016).

7. Chaisty P. Legislative Politics in Russia / in A. Brown Contemporary Russia Politics : a Reader. - Oxford: Oxford University Press, 2001. P. 21.

8. Chaisty P. Gleissner, J. The Consolidation of Russian Parliamentarism: The State Duma 1993 - 1998 / in N. Robinson ed. Institutions and Change in Russian Politics. - Basingstoke: MacMillan, 2000. P. 22.

9. Remington Thomas F., Smith Steven S. Theories of Legislative Institutions and the Organization of the Russian Duma // American Journal of Political Science, - 1998. - Vol. 42 / 2. - P. 543-569

10. Sakwa, R. Russian politics and society. London: Routledge, 2008. P. 32.

11. Remington Thomas F. The Russian Parliament: Institutional Evolution in a Transitional Regime, 1989 - 1999. - New Haven, CT \& London : Yale University Press, 2001. P. 23.

12. Chaisty P., Schleiter P. Productive but not Valued: the Russian State Duma, 1994 - 2001 // Europe-Asia Studies. - 2002. №54 (5). - pp. $701-724$.

13. Remington Thomas F. Majorities without Mandates: The Russian Federation Council Since 2000 // Europe-Asia Studies. 2003. № 55(5). P. 667-691.

14. Chaisty P. Legislative Politics and Economic Power in Russia. - Basingstoke: Palgrave, 2006. P. 34.

15. Remington Thomas F. Patronage and the Party of Power: President - Parliament Relations Under Vladimir Putin // EuropeAsia Studies, - 2008. - №60 (6). - P. 959 - 987.

16. Sakwa R. Putin's Leadership: Character and Consequences // Europe-Asia Studies, - 2008. - №60 (6). - P. 879 - 897.

17. Tsygankov A.P. Mezhdu liberal'noi demokratiei i spolzaniem v avtoritarizm: predvaritel'nye itogi politicheskogo razvitiya Rossii // Sotsial'no-politicheskii zhurnal. 1997. №1. S. 15 - 37.

18. Chepus A.V. Pravitel'stvo Rossiiskoi Federatsii: sostav i poryadok ego formirovaniya // Politika i Obshchestvo. - 2015. - 2. C. 230 - 240. DOI: 10.7256/1812-8696.2015.2.14459.

19. Sergeeva S.L. Osobennosti natsional'noi politicheskoi kul'tury: sotsiokul'turnaya spetsifika i perspektivy razvitiya v usloviyakh sovremennoi rossiiskoi deistvitel'nosti // Politika i Obshchestvo. - 2013. - 10. - C. 1286 - 1301. DOI: 10.7256/18128696.2013.10.9838 